\title{
Design Of Tumor Image Data Server Aplication Using ITK Library (Insight Toolkit)
}

\author{
Meikolin Saimara \\ Department Of Electrical Engineering, University Of North Sumatra, Jl. Dr. Mansur No. 9 Padang Bulan, Kec. \\ Medan Baru, Kota Medan 20222
}

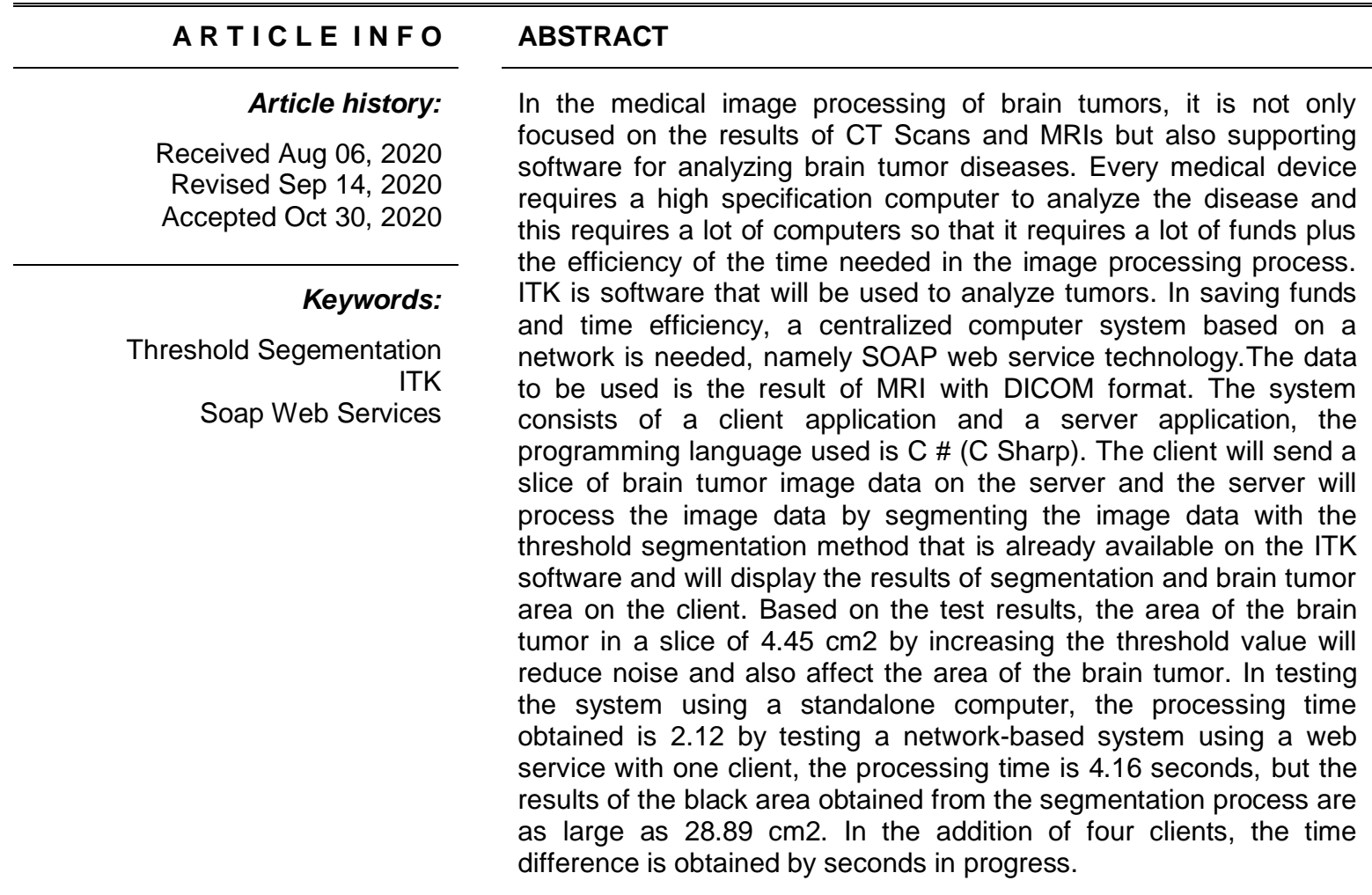

This is an open access article under the CC BY-NC license.

Corresponding Author:
Meikolin Saimara,
Department Of Electrical Engineering,
University Of North Sumatra,
JI. Dr. Mansur No. 9 Padang Bulan, Kec. Medan Baru, Kota Medan 20222.
Email : meikolinsaimara@gmail.com
1. INTRODUCTION
In the development of technology in the medical field, especially in medical images, technology that
can diagnose a disease area is known as CT Scan and MRI. Computed Tomography Scan (CT
Scan) is a diagnostic test that has very high information. The main purpose of using CT Scan and
MRI is to detect intracranial hemorrhage, lesions that fill the brain cavity. Magnetic Resonance
Imaging (MRI) is different from CT Scan, in that MRI does not use ionizing radiation but uses a
magnetic field and radiofrequency. By using CT Scan and MRI the results of the brain tumor image


data must be reprocessed using a computer so that it can be visualized and analyzed. Along with the development of network-based systems and also the development of image processing technology, especially in the medical field, which is growing rapidly,

There are many medical image processing applications available for research and diagnostic purposes. However, most of this software is only available in local or standalone applications. Every medical equipment requires a standalone computer to process medical image data, if every medical image equipment requires a standalone computer, it takes a lot of computers that have the ability to process image data and this requires no small amount of funds plus the required time efficiency. in image processing. To overcome this, we need a centralized system in image data processing, namely by developing tools based on web services technology.

Web services technology is one of the technologies designed to support computers on a network-based system to build tumor image data applications. By using web services technology, there will be two applications to be built, namely the application on the server and the application on the client. In the application for the client, a Graphical User Interface (GUI) based application can be used which will later be operated on the client side and will require an installation process on the client side.

In this study, several literature reviews were carried out on previous studies. In research conducted on Mohammed . discusses how to compress large image data without losing data from the image, making it easier to transfer data. In a study conducted by Marcelo Dorn Busch Lopez. Discusses how to analyze Network via the web with JPEG and PNG image formats. In a study conducted by Lara tramontan. More focus on encrypted communication between Client side programs and server side software obtained with java and php programming interfaces. In a study conducted by Sayed Ehsan Mahmodi discusses a medical image processing system based on web visualization using a pure web programming language and does not require installation on the inside of its use. In a study conducted by Spiros Koulouzis [6] discusses the transportation of 2D analysis image visualization data for medical image analysis using web services technology. The web service technology used is the Simple Object Access Protocol (SOAP).

\section{RESEARCH METHOD}

\subsection{Design Instruments}

This design instrument uses medical image data in the DICOM (Digital Imaging and Communication in Medicine) format which will be processed by the system. DICOM (Digital Imaging and Communication in Medicine) is a provision on medical imaging and communication in medicine created by the National Electrical Manufactures Association (NEMA) to support the distribution and review process of medical images, such as CT Scan, MRI and Ultrasound. Meanwhile, if the Dicom format data must be converted to JPEG format, the data will be lossy, which means reducing the size of the data by removing some parts of the data in the conversion so that the authenticity of the data is not intact.

The software that will be used in this design includes using the C Sharp programming language because $\mathrm{C}$ Sharp is supported by the dot Net framework which is easy to use and has support for web services. Other software used in this design is the ITK library. In this study also uses a server and the server that will be used is IIS Express.

\subsection{System Testing Method}

In the web service testing method using a star network topology and by using a Local Area Network (LAN). As for the specifications of hardware with 1 computer as a server, 8 computers as a client.

The specifications of the server computer are as follows:

a. Memory of $2 \mathrm{~GB}$

b. Intel core i3 processor $1.90 \mathrm{GHz}$

c. Windows 732 bit Operating System The specifications of the client computer.

d. Memory of $2 \mathrm{~GB}$

e. Windows 732 bit operating system

f. Memory of $2 \mathrm{~GB}$ 


\section{g. Windows 732 bit Operating System}

\section{RESULTS AND DISCUSSIONS}

The results of the first test are by comparing two medical images scanned from MRI. Examination for brain MRI is generally carried out using the T1-Weigted Image and T2-Weighted Image sequence techniques. T1-Weighted Image is used to see the anatomy of the brain while T2 Weighted Image aims to see pathology or abnormalities that occur in the brain area. The test is carried out on a network-based system using a web service to see the results of segmentation and display the area of the brain that contains a tumor. The test results then compare the processing time using a standalone computer with one client. Processing time is the total time from the delivery process to the return process. In the next test, because the system is network-based using a web service, it is carried out using multi-clients: from four to twelve simultaneously. This is done to see the processing time of sending medical images from the process of returning the segmentation results if there are additional clients.

In network-based testing using a web service, it is carried out in the Comlabs room of the Department of Electrical Engineering, University of North Sumatra.

\subsection{Test Results Show Brain Tumor}

The first test will display and compare a slice of the same data from T1-Weigted Image and a slice of data from T2-Weighted Image with the same patient and setting the same threshold value so that later information about the brain tumor is obtained.

Because the image uses threshold segmentation, the resulting image is a binary image in the form of a black and white image.

\section{a. T1-Weigted Image}

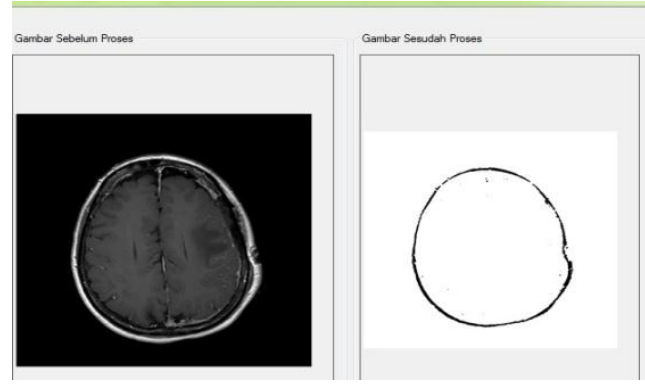

Figure 1. Threshold 100

Figure 1 is the result of segmentation with a threshold value of 100 with a black area of 15.98 $\mathrm{cm} 2$.

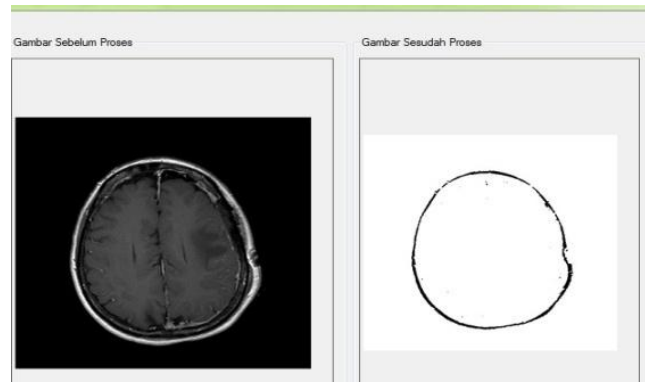

Figure 2. Threshold 110 

$\mathrm{cm} 2$.

Figure 2 is the result of segmentation with a threshold value of 110 with a black area of 13.66
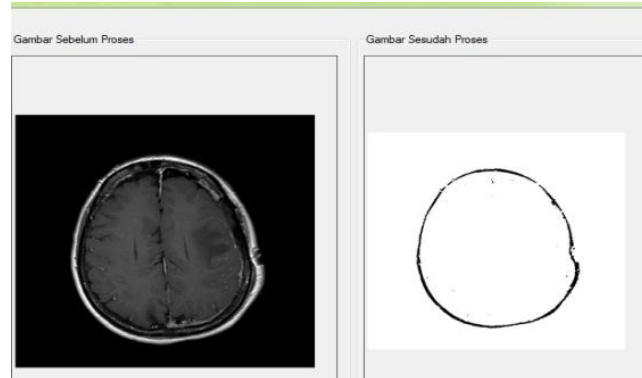

Figure 3. Threshold 120

Figure 3 is the result of segmentation with a threshold value of 120 with a black area of 11.58 $\mathrm{cm} 2$.
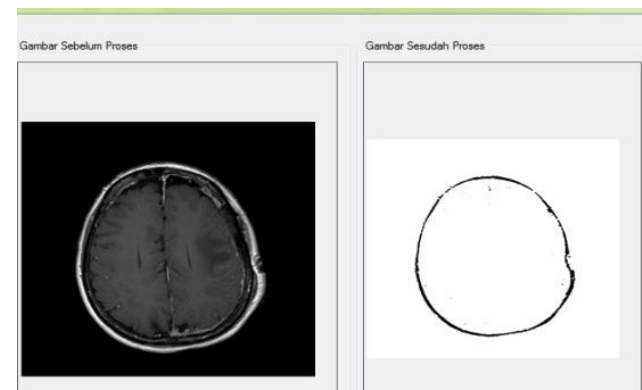

Figure 4. Threshold 130

Figure 4 is the result of segmentation with a threshold value of 130 with a black area of 9.52 $\mathrm{cm} 2$.

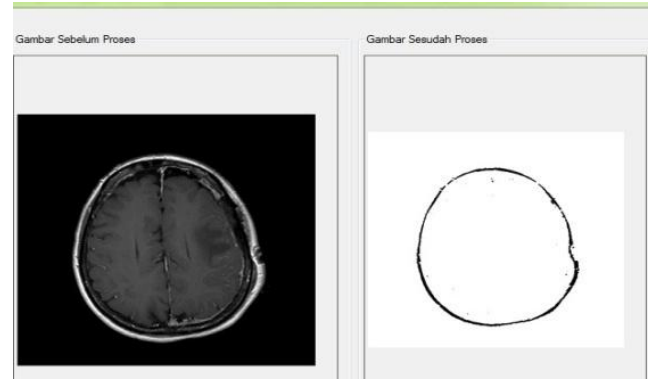

Figure 5. Threshold 140

Figure 5 is the result of segmentation with a threshold value of 140 with a black area of 7.44 $\mathrm{cm} 2$

\section{b. T2-Weighted Image}




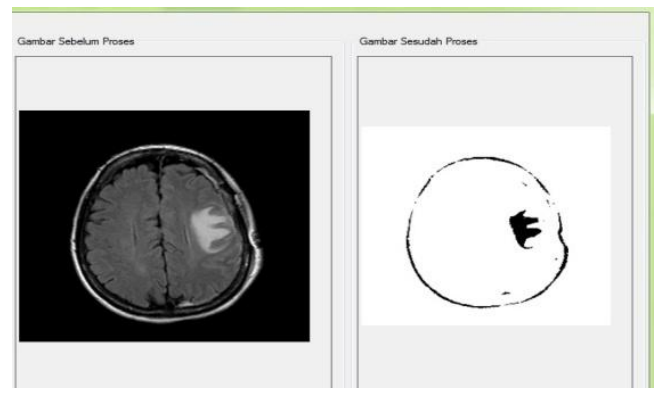

Figure 6. Threshold 100

Figure 6 is the result of segmentation with a threshold value of 100 with a black area of 23.19 $\mathrm{cm} 2$.

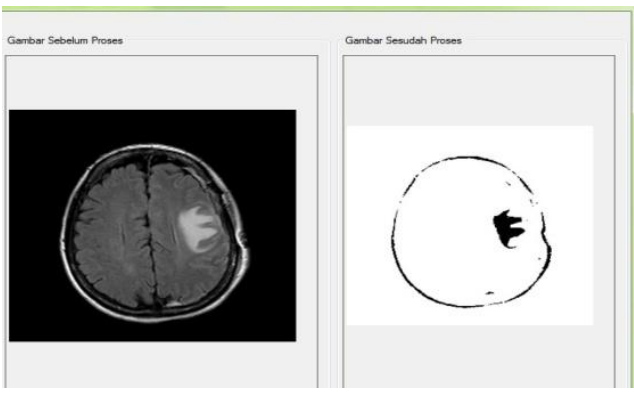

Figure 7. Threshold 110

Figure 7 is the result of segmentation with a threshold value of 110 with a black area of $19.09 \mathrm{~cm} 2$.

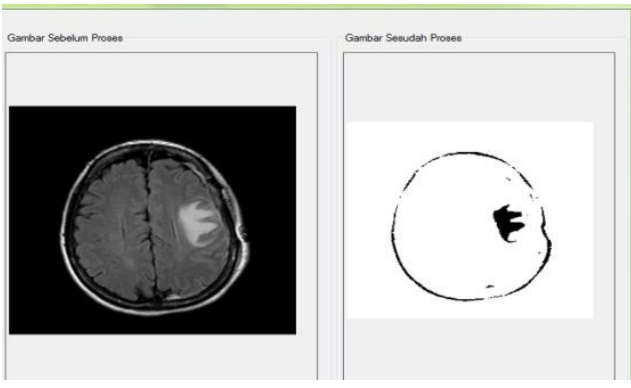

Figure 8. Threshold 120

Figure 8 is the result of segmentation with a threshold value of 120 with a black area of 15.95 $\mathrm{cm} 2$. 


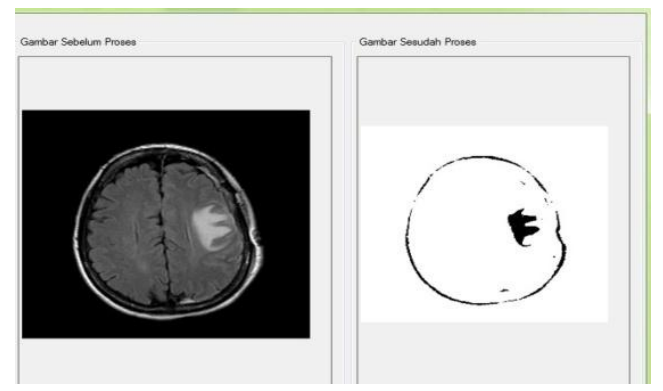

Figure 9. Threshold 130 $\mathrm{cm} 2$.

Figure 9 is the result of segmentation with a threshold value of 130 with a black area of 12.81

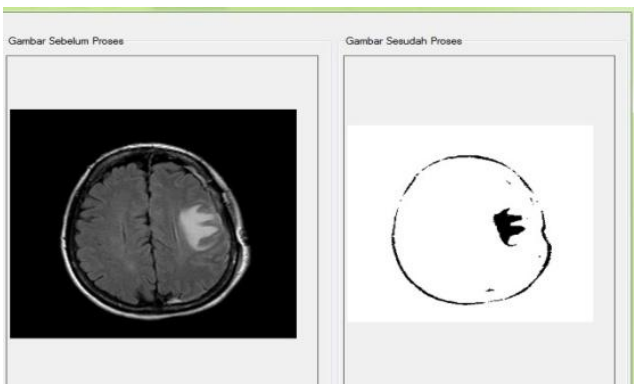

Figure 10. Threshold 140

Figure 10 is the result of segmentation with a threshold value of 140 with a black area of 9.4 $\mathrm{cm} 2$.

In the tests carried out, the results can be seen, by setting the threshold value it will clarify the appearance of the tumor image. Setting the threshold value is needed to reduce noise or disturbance in the image, noise can cause the object to be analyzed to be difficult to see or study, but if the threshold value continues to be increased then the appearance of the tumor will become white and reduce the area of black areas this is because the gray level increases.

Table 1. Black Area T1- Weighted Image

\begin{tabular}{cc}
\hline Threshold & $\begin{array}{c}\text { Black Area } \\
\text { ( cm2 ) }\end{array}$ \\
\hline 100 & 15.98 \\
110 & 13.66 \\
120 & 11.58 \\
130 & 9.52 \\
140 & 7.44 \\
\hline
\end{tabular}

Table 2. Black Area T2-Weighted Image

\begin{tabular}{cc}
\hline Threshold & $\begin{array}{c}\text { Black Area } \\
\text { ( } \mathbf{c m} 2 \text { ) }\end{array}$ \\
\hline 100 & 23.19 \\
110 & 19.09 \\
120 & 15.95 \\
130 & 12.81 \\
140 & 9.4 \\
\hline
\end{tabular}




\subsection{Network-Based System Testing Using a web service}

In testing a network-based system using a web service, starting with getting the processing time using a standalone application and then testing a web service-based system with one client. The image data used in the test is $166 \mathrm{~KB}$.
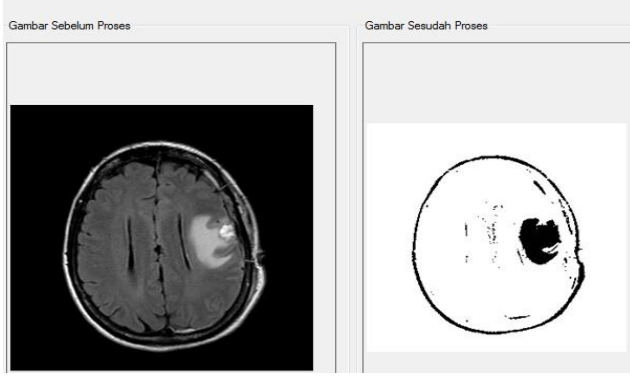

Figure 11. Standalone

In Figure 11 Standalone has a black area of $28.88 \mathrm{~cm} 2$ with a processing time of 2.12 seconds.

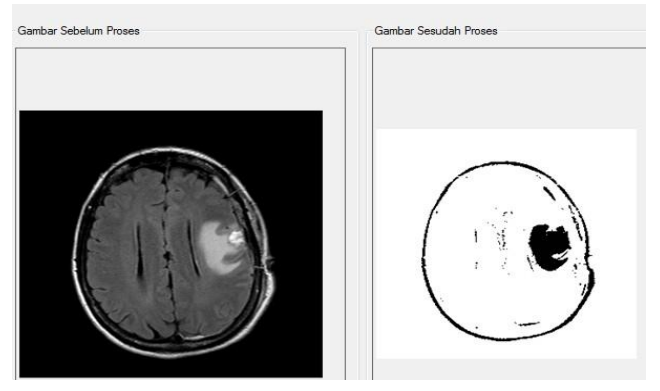

Figure 12. One Client

In Figure 12 One client has a black area of $28.88 \mathrm{~cm} 2$ with a processing time of 4.16 seconds

In system testing, it can be seen that the processing time difference from a standalone application with a network-based system using a web service is 2.4 seconds, but the black area obtained remains the same, which is $28.88 \mathrm{~cm} 2$.

\subsection{Multi Client Testing}

In a network-based system using a web service, the use is shown for more than one client, so testing is done with many clients (multi-client). Multi-client testing is carried out to see the effect of the number of clients that can be served by the server in the process of sending, segmenting and returning results. The image data used in the test is $166 \mathrm{~KB}$.

Table 3. Experiment With Four Clients

\begin{tabular}{cc}
\hline & Processing Time (Second) \\
\hline PC1 & 4.10 \\
PC2 & 4.09 \\
PC3 & 8.02 \\
PC4 & 7.14 \\
\hline
\end{tabular}

Table 4. Experiment With Eight Clients

\begin{tabular}{cc}
\hline & Processing Time (Second) \\
\hline PC1 & 5.22 \\
PC2 & 6.12 \\
PC3 & 4.10 \\
\hline
\end{tabular}


At the testing stage, there is an increase in the average time both in sending images and returning image results at each additional client, however, the increase in time is not too large.

\subsection{System Reliability Analysis}

Based on the tests carried out on the system, the results of the medical image processing design were obtained. The test results to be analyzed consist of two parts: the first to calculate the area of the brain tumor image and the second to calculate the time for each additional client.

The first test result to be analyzed is the area of the tumor image in the system. To find out the area of the image, the thing that must be done is to calculate the difference between the average black area of T2-Weighted Image and the average black area of T1-Weighted Image, in calculating the difference between the average black area of T2-Weighted Image and T1-Weighted Image does not take into account the pixel distance and the number of pixels in the T1-Weighted Image and T2-Weighted Image data.

\section{CONCLUSION}

In focusing the brain tumor to be studied, it is necessary to set a threshold value in order to obtain the appearance of a brain tumor.

There is a difference in processing time for each additional client. The results of the calculation of the area obtained from testing a standalone-based computer system are no different from the results obtained from testing a network-based computer using a web service.

In the design of 2D tumor analysis to analyze images, there has not been a way to remove the outer skull on the outer brain automatically, although there will be additional software that is based on Visualization and requires more than one image to send it requires a datasheet from the brain.

\section{REFERENCES}

Cook, J Louis and Jefri Freedman. Brain Tumors, New York : Rosen Publishing Group, 2012.

Seyyed Ehsan Mahmoudi et al., "Web-based interactive 2D/3D medical image processing and visualization software," Computer Methods and Programs in Biomedicine, pp. 172-182, November 2010.

Mahmoud Mohamed Shaiboun, Mohamed Shaheen, "Streaming Medical Images Using Video Compression, " in IEEE Workshop on ICT Solutions For eHealth, 2016.

Marcelo DornBusch Lopez et al, " A Web-Based Tool For Semi-Automated Segmentation of Histopathological Images Using Nonlinear Color Classifiers".

Lara Tramontan, Enea Poletti, Diego Fiorin and Alfredo Ruggeri, “ A Web- Based System for the Quantitative and Reproducible Assessment of Clinical Indexes From the Retinal Vasculature," in IEEE Transactions on Biomedical Engineering, Vol.58, No. 3, March 2011.

Spiros Koulouzis, Elena Zudilova-Seinstra, and Adam Belloum, " Data Transport between Visualization Web Services for Medical Image Analysis," in International Conference on Computational Science, ICCS 2010, 2010.

Ibanez Luis, Hans J.Johnson, Matthew M. McCormick, and the Insight Software Consortium, The ITK Software Guide, Fourth Edition ed.,2014.

Rhollysatn. 2010.Citra Medis [Online]. https://rhollysatn.wordpress.com/2010/10/22/citra-medis-medicalimaging

J.C.Russ, The Image Processing Handbook, 3rd ed. Florida: CRC Press, 1998.

Prasetyo,Eko. 2011. Pengolahan Citra Digital dan Aplikasinya Menggunakan Matlab. Yogyakarta: Andi.

Adollah, R,"Blood Cell Image Segmentation: A Review,”. Biomed. Proc. 21, 141-144(2008).

K. Abdul dan Adhi Susanto, Teori dan Aplikasi Pengolahan Citra. Yogyakarta, Indonesia: Andi, 2012.

Academic press, Handbook of Medical Imaging Processing and Analysis, Isaac N.Bankman, Ed. :Academic press 2000.

Gonzalez, Rafael C., and Woods, Richard E., "Digital Image Processing”, New Jersey : 2002.

Jianguo Zhang, Kai-Kuang Ma, Meng Hwa Er and Vincent Chong, "Tumor segmentation from magnetic resonance imaging by learning via one-class support vector machine".

Kalin, Martin, "Java Web Services Up and Running”, United State of America: 2009.

w3schools.com. (2015, April) w3schools.com. [Online]. http://www.w3schools.com/xml/xml wsdl.asp

w3schools.com. (2015, April) w3schools.com. [Online]. 